\title{
Evaluating implementation of the International Classification of Functioning, Disability and Health in Portugal's special education law
}

Manuela Sanches-Ferreira, Rune J. Simeonsson, Mónica Silveira-Maia \& Sílvia Alves

\begin{abstract}
This paper reports the results of a national two-year project, commissioned by the Portuguese Ministry of Education, to investigate the implementation of the International Classification of Functioning, Disability and Health (ICF) under Decree-Law 3/2008. The Decree-Law also introduced the principle that the documentation of students' functioning profiles should be the basis for eligibility decision-making - replacing the need of a diagnosis. Of specific interest was the study of the ICF implementation in the assessment, eligibility and intervention processes of students in need of specialised supports. To that end, the study was based on a document analysis of case records of 214 students. The analysis of functioning profiles showed that the ICF use promoted a functional approach in students' assessment. In addition, the use of the ICF contributed to the differentiation of eligible and non-eligible students based on their functioning profiles and addressed the most suitable educational interventions within the Individualised Education Plans.
\end{abstract}

\section{Keywords}

special education, legislation, ICF, functioning profiles

\section{Background}

Special education in the last three decades has been characterised by significant philosophical and conceptual changes with associated implications for policy and practice. These changes have occurred in the context of societal awareness of human rights (e.g. UN Conventions on the Rights of the Child 1989 and the Rights of Persons with Disabilities 2006) and corresponding obligations to eliminate discrimination and segregation. This awareness contributed to the rejection of a medical model of disability based on the diagnosis of impairments and to the conceptualisation of disability based on the person's interaction with the environment. This changing conception has taken the form of a new paradigm of disability in which the environment plays a central role in the process of disablement (Verbrugge and Jette 1994) reflected in the universal language of declarations, such as the UN Millennium Development Goals and the Education for All (UN 2000). With reference to classification systems, the change was from a unidirectional relationship linking impairments, disabilities and handicaps (WHO 1980) to ones recognising the impact of the environment on individual's disability (IOM 1997). This view is described as the biopsychosocial model, which 'synthesizes what is true and useful in the medical and social models, without making the mistake each makes in reducing the whole, complex notion of disability to one of its aspects' (Üstun et al. 2003, 568). The publication of the International Classification of Functioning, Disability and Health (ICF) (WHO 2001) offered a framework reflecting the principles of a biopsychosocial approach and provided a systematic approach to substantiate the students' needs (Simeonsson et al. 2003). In its interactional model the ICF defines functioning as 'the positive aspects of the interaction between an individual (with a health condition) and that individual's contextual factors (environmental and personal factors' (WHO 2001, 212). 
The changing conceptions of disability have also influenced national laws pertaining to services for adults and special education for children (Van Swet, Wichers-Bots, and Brown 2011). A primary basis for the laws was the acknowledgement of the effects of prejudice and discrimination on labelling of students and the importance of a language to describe the complexity of student characteristics and their functioning. Central to this perspective was the need for a functional approach to assess and classify disability in childhood (Simeonsson, Simeonsson, and Hollenweger 2008). In this context, the primary role of environmental factors in the disability process was recognised (Simeonsson et al. 2003). The direction adopted in conceptualisations of disability consisted in abandoning the 'within-child' conceptualisations towards ones that recognise the interaction with environmental factors (Florian et al. 2006; Wedell 2008).

The need for a holistic conceptual framework for education of children with special needs is well met with the person-environment fit approach (Soresi, Nota, and Wehmeyer 2011) of the ICF in that it promotes a

... better fit between students' capacities and the educational context. ... has the potential of increasing the quality of inclusive practices and consequently respond to the ethical demands that postulate everyone's right to be part of social valued activities and roles. (Silveira-Maia et al. 2012, 970)

Specifically, the ICF offers an organised schema for the categorisation of Body Functions, Body Structures, Activities and Participation and Environmental Factors (ICF components), which allows a comprehensive description of student's functioning. The individual's 'execution of a task or action' and 'involvement in a life situation' (Activities and Participation) comprises a visible outcome from the interaction between physiological systems and anatomical parts of the body (Body Functions and Body Structures) and the physical, social and attitudinal environment in which people live and conduct their lives (Environmental Factors). These components are represented by chapters and codes embodying standard operational definitions of health and health-related functions. An additional ICF contribution to document human functioning is the use of severity qualifiers, defining the extent of functioning or disability in each described code, which can range from 0 ('no problem') to 4 ('complete problem'). Thus, the ICF is seen as a framework that can guide practitioners to adopt a functional approach for assessing students and monitoring their progresses over time (Simeonsson et al. 2003, 2010). These recognised potentialities motivated several international pilot experiences that have been studying the ICF use on special education assessment and eligibility processes. Italy (De Polo et al. 2009; Fusaro, Maspoli, and Vellar 2009), Switzerland (Hollenweger2011) and Japan (Tokunaga 2006, 2008) are some of the more widely documented examples.

The classification and categorisation of childhood disability emerged with the main intention to ensure a common understanding and application of eligibility criteria (Hollenweger 2008; Wedell 2008). According to Riddell (2008), the classification systems are important 'because they reveal a great deal about dominant discourses and underlying relationships of knowledge and power' (109). The conceptualisation of differences among children guides policy decisions and educational practices in assessment of students as well as in intervention. In the special education field, it impacts the provision of services and allocation of resources to increase the participation of students in contexts in which they have to function (Florian et al. 2006; Hollenweger 2008). 
In spite of the changing views of disability described above, the classification of childhood disability for eligibility determination for additional supports has been identified as a measure of discrimination, even in the case of positive discrimination (Ebersold and Evans 2008). The importance of educational equity has therefore inspired advances regarding special education legislation in many countries including Portugal. In 2008, the Portuguese Ministry of Education advanced a policy stating 'Inclusive education aims for educational equity ... whether in access or in outcomes ... conducive to the mobilization of specialized services to promote the biopsychosocial functioning potential'. The enactment of Decree-Law 3/2008 (DL 3/2008) prescribed a new approach for defining the target group of students for special education services as those with

significant limitations in terms of activity and participation in one or more areas of life, due to structural and functional permanent changes resulting in continued difficulties in communication, learning, mobility, autonomy, interpersonal relationships and social participation. (Paragraph 1 of Article 1st, Chapter I)

In line with this approach, DL 3/2008 introduced the principle that documentation of ICF profiles of student functioning should be the basis for eligibility determination - replacing the need for a diagnosis. When a student is referred for assessment, the school interdisciplinary team has to decide, based on available reports and information, if the student needs a specialised assessment. The final product of the specialised assessment is the functioning profile of student described using the ICF taxonomy and based on which the eligibility for special education services is determined.

In order to evaluate the implementation of DL $3 / 2008$, specifically the use of the ICF framework, the Ministry of Education invited an external team to conduct a national evaluation study. That wide study, 'External Evaluation Project of Decree-Law 3/2008 Implementation' (SanchesFerreira et al. 2010) was carried out during 2009 and 2010, and included the evaluation of the decisions taken by schools in the students' processes of assessment and eligibility based on a nationally collected sample of 214 students subjected to a specialised assessment. The functioning profiles of students were analysed and revealed that functioning profiles of eligible students are congruent with the requirements from the above-mentioned definition of the target group for special education services (Sanches-Ferreira et al. 2010, 2013). Specifically, functioning profiles of eligible students for special education services - therefore, with an Individualised Education Plan (IEP), $n=156$ - do not differ from the ones of non-eligible students, $n=58$, in the mean number of ICF codes, but rather on the level of severity of qualifiers assigned to ICF codes.

Further to support the eligibility decision-making, functioning profiles should also serve as the source for planning educational intervention strategies focused on students' participation. The provision of additional educational interventions in Portuguese schools ranges from adaptations and accommodations to access general curriculum to highly specialised curricula (HSCs), in which the student's functioning in life contexts is prescribed ( $D L 3 / 2008$, article $21^{\circ}$, point 3 ). A more functional curriculum is defined for students with more severe disabilities and is directed to prepare students in life skills required for all aspects of an independent everyday functioning and anticipate their transition for post-school life (Sanches-Ferreira et al. 2013). 
Therefore, based on data from the 'External Evaluation Project of Decree-Law 3/2008 Implementation' report, the aim of this paper is to describe how the use of the ICF contributed to changes in special education policy and practices, namely in the process of determining eligibility and provision of educational interventions for students with special education needs in Portuguese schools. Further, we aim to understand how the ICF has contributed to describe the continuum of functioning of students with IEP. This can be broken into the following research questions:

1. What are the ICF codes and qualifiers used to describe functioning profiles of students with IEP?

2. How different are functioning profiles among students with IEP, namely students with HSC and the others with less restrictive educational interventions?

\section{Method \\ Participants}

We conducted a systematic analysis of case reports of individual students to study the use of the ICF in the special education referral to assessment and determination of eligibility. These documents were selected through a randomised sampling procedure, stratified according to the number of eligible students in the five Regional Directorates of Education in Portugal and within grade levels. This resulted in a sample size of 214 students from which case reports could be reviewed with reference to functioning profiles using the ICF taxonomy. The gender distribution of the sample was $66.8 \%$ boys and $33.2 \%$ girls and was mainly from elementary schools (42.7\%). The mean age of the students was 12 years (range from 6 to 19 years) and they presented the following primary health conditions: intellectual disability $(13.6 \%)$, syndromes $(10.7 \%)$, pervasive developmental disorders $(7.0 \%)$, dyslexia $(6.5 \%)$, attention deficit hyperactivity disorder (6.5\%), cerebral palsy (6.1\%) and developmental delays (5.1\%).

\section{Procedures}

Schools principals were contacted to obtain permission for access to student records for data collection and analysis. We asked schools principals to provide, specifically two standard documents developed by the educational team: (a) the Technical and Pedagogical Report - this report is developed after the specialised assessment and includes the identification of functioning characteristics of students - functioning profile - reasons supporting decisionmaking regarding eligibility and selected educational measures and (b) the IEP where the educational interventions underpinned by special education services were described in detail. Confidentiality of the collected information was assured by assigning a numeric code to each student's data record, with no reference to personal information of students, their school or their regional directorate of education.

\section{Analysis}

In order to examine the decisions taken by schools in the process of eligibility determination the analysis focused on identification of functioning characteristics of students (functioning profile) and the educational interventions they received (described in the IEP). The identification of characteristics of functioning, served the basis for making frequency counts of applicable ICF categories and qualifiers. This implied the registration of all codes and qualifiers embodying the descriptions of the students' functioning profiles. Once the IEPs analysed were subsequent to 
the Decree-Law 3/2008 implementation, it was expected that the use of the ICF terminology in functioning profiles, however, not all fulfilled this requirement. Therefore, in order to ascertain the frequency count of ICF codes the following procedures were carried out: (1) if the functioning profile was composed by qualitative descriptions using the ICF terminology, it was subjected to a manifest content analysis - as suggested by Graneheim and Lundman (2004), to establish the codes present in it; (2) if the functioning profile was composed by qualitative descriptions without using the ICF terminology, it was submitted to latent content analysis of meaningful concepts within the text in order to assign them to ICF categories applying Cieza's linking rules (Cieza et al. 2005).

Five functioning profiles were randomly selected within sample and analysed by three researchers. In this step, the IEP/no IEP status of the students was not identified, and an interrater agreement of $85 \%$ was achieved. After debriefing discussions about disagreements, the process was repeated with other five functioning profiles randomly selected and no identification of the eligibility decision achieving and average inter-rater agreement of $94 \%$. Then the three researchers proceeded to independent coding. The data were compiled into a database for processing and analysis using the Statistical Package for Social Sciences.

Analysis of the data on the 214 students involved comparing functioning profiles: (1) between students eligible and non-eligible for special education and (2) between eligible students receiving different educational interventions. This comparison pretended to contribute for a global perspective on the differences between groups. Analyses involved two dependent variables with one being the mean number of ICF codes (categories) identified in the student's profile of functional characteristics. The other was the mean severity level assigned to the code indicating the degree of impairment of Body Functions or Structures, degree of limitations or restrictions of Activities and Participation, and the extent to which Environmental Factors were barriers.

\section{Results}

To examine how the ICF framework was used to determine eligibility and to develop educational interventions under special education services, we analysed functioning profiles of students based on case record information. To answer the research questions, comparisons were made of the functioning profiles, derived from the educational teams' data, of 156 students found eligible with 58 students found to be non-eligible for special services. Finally, within the group of eligible students we compared the functioning profiles of 91 students whose educational supports included adaptations and accommodations that preserve the general curriculum with those of 65 students provided with a HSC.

\section{(1) What are the ICF codes and qualifiers used to describe functioning profiles of students with IEP?}

The nature of functional characteristics of students eligible and non-eligible for special education services and the mean severity level of functioning profiles (second-level ICF categories) of both groups are given in Table 1 . 
Table 1. Comprehensive functioning profile of eligible and non-eligible students.

\begin{tabular}{cll}
\hline & \multicolumn{1}{c}{$\begin{array}{c}\text { Functioning profile of } \\
\text { eligible students }\end{array}$} & \multicolumn{1}{c}{$\begin{array}{c}\text { Functioning profile of } \\
\text { non-eligible students }\end{array}$} \\
\hline Activities and & d137.3 Acquiring concepts & d140.2 Learning to read \\
Participation & d145.3 Learning to write & d145.2 Learning to write \\
& d150.3 Learning to calculate & d160.2 Focusing attention \\
& d160.3 Focusing attention & d163.2 Thinking, formulating and \\
d161.3 Directing attention & manipulating ideas, concepts and \\
d163.3 Thinking, formulating and & images \\
& manipulating ideas, concepts & d166.2 Reading \\
and images & d170.2 Writing \\
d166.2 Reading & d172.2 Calculating \\
& d170.3 Writing & d175.2 Solving problems \\
d172.3 Calculating & d177.2 Taking decisions \\
d175.3 Solving problems & d325.2 Communicating-with- \\
& d210.3 Undertaking a single task & receiving-written messages \\
d310.3 Communicating-with- & d250.2 Managing behaviour \\
& receiving-spoken messages & d710.2 Establishing basic \\
d350.3 Sustaining a conversation & interpersonal interactions \\
Body & b117.3 Intellectual functions & b126.2 Temperament and personality \\
Functions & b140.3 Attention functions & functions \\
& b144.3 Memory functions & b140.2 Attention functions \\
b147.3 Psychomotor functions & b144.2 Memory functions \\
b156.3 Perceptual functions & b152.2 Emotional functions \\
factors & b164.3 Higher-level cognitive & b164.2 Higher-level cognitive \\
functions & functions \\
& b167.3 Mental functions of language & b167.2 Mental functions of language \\
& e130+3 Products and technology for & e310+3 Support from immediate \\
education & family \\
& e310+3 Support from immediate & e330+3 Support from teachers \\
family & e410+3 Individual attitudes of \\
immediate family members
\end{tabular}

The overall profiles of both groups are similar in form and distribution. The most represented domain on Activities and Participation categories was the learning and applying knowledge mentioned for a mean of 10 and 9 categories in eligible and non-eligible students, respectively. With reference to the Body Functions component, the most frequent categories for both groups were associated with mental functions for a mean of 7 and 6 categories. Finally, the most represented domain on Environmental Factors categories was the supports and relationships with 3 and 2 categories mentions.

Furthermore, whereas more than $80 \%$ of the qualifiers for non-eligible students were mainly at the level 1 (mild) and 2 (moderate), the severity qualifiers of eligible students' profiles were mostly distributed between the levels 2 (moderate) and 3 (severe) on Body Functions and Activities and Participation components.

These results are supportive of the use of the ICF to document functional characteristics of students relevant to determinate eligibility for special education services as defined by DL $3 / 2008$. Specifically, these results are congruent with the law emphasis on basing eligibility decision-making on severity level of impairments and limitations of Body Functions and Activities and Participation, respectively. 


\section{(2) How different are functioning profiles among students with IEP, namely students with HSC and the others with less restrictive educational interventions?}

To test the assumption that the educational system 'should offer a continuum of services based on the idea of personalising education' (Hollenweger 2011, 7), an analysis was made to determine if the selection of educational supports and interventions in IEPs of eligible students differed on the basis of their functioning profiles. To that end, a comparison was made of functioning profiles of eligible students provided with a HSC, $n=65$, with eligible students provided with interventions directed towards support of general curriculum goals, $n=91$ (Table 2).

Table 2. Mean number of categories assigned to each ICF component on functioning profile of students with and without HSC.

\begin{tabular}{lcc}
\hline Components & With HSC $(n=65)$ & Without HSC $(n=91)$ \\
\hline Body Functions & 7.5 & 6.8 \\
Activities and Participation & 16.3 & 10.9 \\
Environmental Factors & 5.2 & 5.0 \\
Total of categories & 29.0 & 22.6 \\
\hline
\end{tabular}

Results indicated that the functioning profiles of students with HSC included a significantly higher number of categories than those without HSC, $t(154)=-2.75, p=.007$. A comparison by components revealed significant differences for Activities and Participation, $t(115.2)=-3.39, p=.001$, whereas the mean number of categories on Body Functions, $t(154)=-.61$, ns, and Environmental Factors, $t(154)=-.45$, ns, did not differ significantly. Comparison of the mean severity levels assigned to functioning profiles of students receiving HSC services and those receiving other services did not reveal any significant difference, Body Functions, $t(136)=.22, n s$; Activities and Participation, $t(150)=-1.8$, ns; Environmental Factors, $t(148)=-.32$, ns. The functioning profiles of students provided HSC versus those provided other services are presented in Table 3. 
Table 3. Comprehensive functioning profile of students with and without a HSC.

\begin{tabular}{|c|c|c|}
\hline & $\begin{array}{l}\text { Functioning profile of } \\
\text { students with HSC }\end{array}$ & $\begin{array}{l}\text { Functioning profile of } \\
\text { students without HSC }\end{array}$ \\
\hline $\begin{array}{l}\text { Activities and } \\
\text { Participation }\end{array}$ & $\begin{array}{l}\text { d137 Acquiring concepts } \\
\text { d140 Learning to read } \\
\text { d145 Learning to write } \\
\text { d150 Learning to calculate } \\
\text { d155 Acquiring skills } \\
\text { d160 Focusing attention } \\
\text { d161 Directing attention } \\
\text { d163 Thinking, formulating and } \\
\text { manipulating ideas, concepts } \\
\text { and images } \\
\text { d166 Reading } \\
\text { d170 Writing } \\
\text { d210 Undertaking a single task } \\
\text { d310 Communicating } \\
\text { with-receiving- } \\
\text { spoken messages } \\
\text { d330 Talking } \\
\text { d350 Sustaining a conversation } \\
\text { d440 Fine hand use } \\
\text { d710 Establishing basic } \\
\text { interpersonal interactions }\end{array}$ & $\begin{array}{l}\text { d150 Learning to calculate } \\
\text { d160 Focusing attention } \\
\text { d161 Directing attention } \\
\text { d166 Reading } \\
\text { d170 Writing } \\
\text { d175 Solving problems } \\
\text { d210 Undertaking a single task } \\
\text { d230 Carrying out daily routines } \\
\text { d250 Managing behaviour } \\
\text { d310 Communicating with-receiving- } \\
\text { spoken messages } \\
\text { d350 Sustaining a conversation }\end{array}$ \\
\hline $\begin{array}{l}\text { Body } \\
\text { Functions }\end{array}$ & $\begin{array}{l}\text { b117 Intellectual functions } \\
\text { b140 Attention functions } \\
\text { b144 Memory functions } \\
\text { b147 Psychomotor functions } \\
\text { b164 Higher-level cognitive } \\
\text { functions } \\
\text { b167 Mental functions } \\
\text { of language } \\
\text { b172 Calculation functions } \\
\text { b320 Articulation functions } \\
\text { b330 Fluency and rhythm of } \\
\text { speech functions }\end{array}$ & $\begin{array}{l}\text { b117 Intellectual functions } \\
\text { b126 Temperament and personality } \\
\text { functions } \\
\text { b140 Attention functions } \\
\text { b144 Memory functions } \\
\text { b152 Emotional functions } \\
\text { b156 Perceptual functions } \\
\text { b167 Mental functions of language }\end{array}$ \\
\hline $\begin{array}{l}\text { Environmental } \\
\text { Factors }\end{array}$ & $\begin{array}{l}\text { e130 Products and technology } \\
\text { for education } \\
\text { e310 Support from immediate } \\
\text { family } \\
\text { e330 Support from teachers } \\
\text { e325 Support from peers } \\
\text { e410 Individual attitudes of } \\
\text { immediate family members }\end{array}$ & $\begin{array}{l}\text { e130 Products and technology } \\
\text { for education } \\
\text { e310 Support from immediate family } \\
\text { e325 Support from peers } \\
\text { e330 Support from teachers } \\
\text { e410 Individual attitudes of } \\
\text { immediate family members }\end{array}$ \\
\hline
\end{tabular}

An inspection of the profiles of students provided with HSC shows problems in Body Functions, including mental functions and speech and voice functions. Although problems of learning and applying knowledge were reported for both groups, the profiles of students provided HSC also reflected problems related to communication, task and general demands, mobility and interpersonal relationships. The inclusion of problems in these domains seems consistent with the focus on areas of functioning in the HSC.

The difference in the nature and number of categories found between these two groups suggests that the ICF framework offers a holistic description of student functioning. Such description can support the educational team's identification of the most appropriate interventions to adopt, representing different nature and intensity of supports. 


\section{Conclusion}

In Portugal, a new law - DL 3/2008 - introduced changes for defining the target population for special education services based on the use of ICF as a common language and framework to guide the assessment and eligibility determination processes. These changes advancing the use of the ICF to document child characteristics in a comprehensive functioning profile require an extensive assessment process of students involving different professionals (De Polo et al. 2009). The results of this study demonstrated that professionals did document student characteristics within a biopsychosocial perspective. Moreover, in keeping with DL 3/2008 definition and requirements, it was found that professionals approached disability in terms of functional assessment of limitations and restrictions in Activities and Participation component.

In addition to providing a systematic basis for documenting profiles of student functioning, the use of the ICF framework also provided the basis for comparing characteristics of eligible and non-eligible students. In fact, DL 3/2008 states that eligible students must have 'significant limitations in terms of activities and participation ... due to structural and functional permanent changes'. Findings on the comprehensive functioning profiles of students eligible and noneligible for special education services support evidences from a previous study (SanchesFerreira et al. 2013) that the main difference between their functioning profiles was in the mean severity level assigned to functioning categories, with the eligible students defined by more severe descriptions in their profiles. This qualitative difference is consistent with the importance of (a) limitations/restrictions of Activities and Participation experienced by students and (b) the permanence of their impairments of Body Functions as requirements for eligibility determination under DL 3/2008. The findings of this study provide support for the requirement in the legislation of a detailed description of student functioning limitations and associated environmental conditions, rather than a medical diagnosis.

In addition, the use of the ICF framework also differentiated educational interventions for eligible students on the basis of their IEP's either for a HSC or interventions based on other supports. The difference consisted in the mean number and nature of the ICF categories focusing primarily on learning and mental functions, whereas few references were found related to functioning in other areas, such as mobility, self-care, domestic and major life domains. These findings suggest the need for a greater focus on areas of participation related to students' autonomy and their involvement in societal life. Further, the results demonstrate that aspects of Environmental Factors component are not broadly implemented, suggesting a limited view of the environment's influence on functioning and participation of the student. That assessment of the environment can offer documentation of barriers and facilitators of student functioning, therefore it is important that tools are developed to assess Environmental Factors. Such assessment can provide information on what the student can do with and without assistance, allowing the identification of an IEP including support of assistive devices, personal assistance for student in the school environment or including the need to work attitudes from people with whom student has to interact in his/her daily routines. In this regard, Hollenweger (2011), in her work about the development of the ICF-based eligibility procedure also highlights the importance of environmental factors to understand 'individual requirements' and promote student's participation in a given educational setting. Furthermore, our findings can also be read in the light of Hollenweger's contribution suggesting for the expansion of the ICF model. This consists in deciding the child's supports needs taking into consideration the vision of the child to be a responsible, happy and healthy citizen with capabilities, competence and the ability to 
adjust to the society's challenges. Therefore, the development of tools to assess the Environmental Factors should bear in mind the question 'what environmental factors does the child need to improve his/her current participation in life situations and to prepare him/her to full participate in society in the future?'.

This study has demonstrated the utility of the ICF as a resource to guide policy and practice in the provision of special education. In the light with Hollenweger's (2011) work to adapt the ICF for educational use in Switzerland, this study demonstrated that the ICF facilitates the comparability across professionals' eligibility decision-making, contributing for a more and 'transparent and equitable distribution of resources' (7).

The availability of the ICF-CY (Version for Children and Youth) (WHO 2007), with specific coverage related to health and functioning of children, offers an expanded basis for further advancing a multidimensional and interactional approach for the special education field.

\section{References}

- 1. Cieza, A., S. Geyh, S. Chatterji, N. Kostanjsek, B. Üstün, and G. Stucki. 2005. "ICF Linking Rules: An Update Based on Lessons Learned." Journal of Rehabilitation Medicine 37 (2): 212218.

- 2. De Polo, G., M. Pradal, S. Bortolot, M. Buffoni, and A. Martinuzzi. 2009. "Children with Disability at School: The Application of ICF-CY in the Veneto Region." Disability and Rehabilitation 31 (1): S67-S73.

- 3. Ebersold, S., and P. Evans. 2008. "A Supply-Side Approach for a Resource-Based Classification System." In Disability Classification in Education: Issues and Perspectives, edited by L. Florian and M. Mclaughlin, 31-46. Thousand Oaks, CA: Corwin Press.

- 4. Florian, L., J. Hollenweger, R. J. Simeonsson, K. Wedell, S. Riddell, L. Terzi, and A. Holland. 2006. "Cross-Cultural Perspectives on the Classification of Children with Disabilities: Part I. Issues in the Classification of Children with Disabilities." The Journal of Special Education 40 (1): 36-45. doi:10.1177/00224669060400010401

- 5. Fusaro, G., M. Maspoli, and G. Vellar. 2009. "The ICF-Based Functioning Profiles of School Children in Care with the Neuropsychiatric Community Services in the Piedmont Region: Evidences for Better Caring and Programming." Disability and Rehabilitation 31 (1): S61-S66. doi: 10.3109/09638280903317922

- 6. Graneheim, U., and B. Lundman. 2004. "Qualitative Content Analysis in Nursing Research: Concepts, Procedures and Measures to Achieve Trustworthiness." Nurse Education Today 24 (2): 105-112. doi: 10.1016/j.nedt.2003.10.001

- 7. Hollenweger, J. 2008. "Cross-National Comparisons of Special Education Classification Systems." In Disability Classification in Education: Issues and Perspectives, edited by L. Florian and M. Mclaughlin, 11-30. Thousand Oaks, CA: Corwin Press.

- 8. Hollenweger, J. 2011. "Development of an ICF-Based Eligibility Procedure for Education in Switzerland." BMC Public Health11 (4): 1-8. doi:10.1186/1471-2458-11-S4-S7

- 9. IOM. 1997. Enabling America: Assessing the Role of Rehabilitation Science and Engineering. Washington, DC: National Academy Press. 
- 10. Riddell, S. 2008. "The Classification of Pupils at the Educational Margins in Scotland: Shifting Categories and Frameworks." In Disability Classification in Education: Issues and Perspectives, edited by L. Florian and M. Mclaughlin, 109-128. Thousand Oaks, CA: Corwin.

- 11. Sanches-Ferreira, M., R. Simeonsson, M. Silveira-Maia, S. Alves, A. Tavares, and S. Pinheiro. 2013. "Portugal's Special Education Law: Implementing the International Classification of Functioning, Disability and Health in Policy and Practice."Disability \& Rehabilitation 35 (10): 868-873. doi: 10.3109/09638288.2012.708816

- 12. Sanches-Ferreira, M., R. Simeonsson, M. Silveira-Maia, S. Pinheiro, A. Tavares, and S. Alves. 2010. Projecto da Avaliação Externa da Implementação do Decreto-Lei n. ${ }^{\circ}$ 3/2008: Relatório Final [External Evaluation Project of Decree-Law No 3/2008 Implementation]. Lisboa: Direcção-Geral de Inovação e de Desenvolvimento Curricular [Lisbon: Directorate-General for Innovation and Curriculum Development]. Accessed February 3. http://www.dgidc.minedu.pt/educacaoespecial/data/ensinoespecial/estudo_simeonsson.pdf

- 13. Silveira-Maia, M., P. Lopes-dos-Santos, M. Sanches-Ferreira, A. Tavares, S. Alves, and S. Pinheiro. 2012. "The Use of the International Classification of Functioning, Disability and Health (ICF) Framework on Educational Planning: Promoting an Environmental Approach." International Journal for Cross-Disciplinary Subjects in Education 2 (2): 970-977.

- 14. Simeonsson, R. J., M. Leonardi, D. Lollar, E. Bjorck-Akesson, J. Hollenweger, and A. Martinuzzi. 2003. "Applying the International Classification of Functioning, Disability and Health (ICF) to Measure Childhood Disability." Disability and Rehabilitation 25 (11-12): 602-610. doi: $10.1080 / 0963828031000137117$

- 15. Simeonsson, R. J., A. Sauer-Lee, M. Granlund, and E. Bjorck-Akesson. 2010. "Developmental and Health Assessments in Habilitation with the ICF-CY." In Rehabilitation and Health Assessment: Applying ICF Guidelines, edited by E. Mpofu and T. Oakland, 27-46. New York: Springer.

- 16. Simeonsson, R. J., N. E. Simeonsson, and J. Hollenweger. 2008. "International Classification of Functioning, Disability and Health: A Common Language for Special Education." In Disability Classification in Education: Issues and Perspectives, edited by L. Florian and M. Mclaughlin, 207-226. Thousand Oaks, CA: Corwin.

- 17. Soresi, S., L. Nota, and M. L. Wehmeyer. 2011. "Community Involvement in Promoting Inclusion, Participation and Self-determination." International Journal of Inclusive Education 15 (1): 15-28. doi: 10.1080/13603116.2010.496189

- 18. Tokunaga, A. 2006. "Trends and Perspective of the Use of International Classification of Functioning, Disability and Health (ICF) on Special Needs Education in Japan." Journal of Special Education in the Asia Pacific 2: 17-30.

- 19. Tokunaga, A. 2008. "The Attempt of the Practical Application of International Classification of Functioning, Disability, and Health (ICF) as a Tool for Collaboration among Various Professionals: A Perspective on Its Applicability to Individualized Educational Support Plan." NISE Bulletin 9: 1-26.

- 20. UN (United Nations). 1989. UN Convention on the Rights of the Child. New York: United Nations.

- 21. UN (United Nations). 2000. UN Millennium Declaration. New York: United Nations.

- 22. UN (United Nations). 2006. UN Convention on the Rights of Persons with Disabilities. New York: United Nations.

- 23. Üstun, B. T., S. Chatterji, J. Bickenbach, N. Kostanjsek, and M. Schneider. 2003. "The International Classification of Functioning, Disability and Health: A New Tool for Understanding 
Disability and Health." Disability and Rehabilitation 25 (11-12): 565-571. doi: 10.1080/0963828031000137063

- 24. Van Swet, J., J. Wichers-Bots, and K. Brown. 2011. "Solution-Focused Assessment: Rethinking Labels to Support Inclusive Education." International Journal of Inclusive Education 15 (9): 909-923. doi: 10.1080/13603110903456615

- 25. Verbrugge, L. M., and A. M. Jette. 1994. "The Disablement Process." Social Science and Medicine 38 (1): 1-14. doi:10.1016/0277-9536(94)90294-1

- 26. Wedell, K. 2008. "Evolving Dilemmas about Categorization." In Disability Classification in Education: Issues and Perspectives, edited by L. Florian and M. Mclaughlin, 47-67. Thousand Oaks, CA: Corwin Press.

- 27. WHO. 1980. International Classification of Impairments, Disabilities, and Handicaps (ICIDH). Geneva: WHO.

- 28. WHO. 2001. International Classification of Functioning, Disability and Health (ICF). Geneva: WHO.

- 29. WHO. 2007. International Classification of Functioning, Disability and Health - Version for Children and Youth (ICF-CY). Geneva: WHO. 